\title{
Long-term outcomes after endoscopic endonasal surgery for nonfunctioning pituitary macroadenomas
}

\author{
Mina M. Gerges, MD, ${ }^{1,2}$ Kavelin Rumalla, BA, ${ }^{6}$ Saniya S. Godil, MD, ${ }^{1,3}$ lyan Younus, BS, ${ }^{5}$ \\ Walid Elshamy, MD, ${ }^{2}$ Georgiana A. Dobri, MD, ${ }^{1,7}$ Ashutosh Kacker, MD, ${ }^{4}$ Abtin Tabaee, MD, ${ }^{4}$ \\ Viay K. Anand, MD, ${ }^{4}$ and Theodore H. Schwartz, MD ${ }^{1,4}$
}

\begin{abstract}
Departments of ${ }^{1}$ Neurosurgery, ${ }^{4}$ Otolaryngology, and ${ }^{7}$ Endocrinology, Weill Cornell Medicine, NewYork-Presbyterian Hospital, New York; ${ }^{5}$ Weill Cornell Medical College, New York, New York; ${ }^{2}$ Department of Neurosurgery, Faculty of Medicine, Ain Shams University, Cairo, Egypt; ${ }^{3}$ Department of Neurosurgery, Vanderbilt University Medical Center, Nashville, Tennessee; and ${ }^{6}$ Department of Biomedical and Health Informatics, University of Missouri-Kansas City School of Medicine, Kansas City, Missouri
\end{abstract}

\begin{abstract}
OBJECTIVE Nonfunctioning pituitary adenomas are benign, slow-growing tumors. After gross-total resection (GTR) or subtotal resection (STR), tumors can recur or progress and may ultimately require additional intervention. A greater understanding of long-term recurrence and progression rates following complete or partial resection and the need for further intervention will help clinicians provide meaningful counsel for their patients and assist data-driven decision-making. METHODS The authors retrospectively analyzed their institutional database for patients undergoing endoscopic endonasal surgery (EES) for nonfunctioning pituitary macroadenomas (2003-2014). Only patients with follow-up of at least 5 years after surgery were included. Tumor volumes were measured on pre- and postoperative MRI. Tumor recurrence was defined as the presence of a $0.1-\mathrm{cm}^{3}$ tumor volume after GTR, and tumor progression was defined as a $25.0 \%$ increase in residual tumor after STR.
\end{abstract}

RESULTS A total of 190 patients were included, with a mean age of $63.8 \pm 13.2$ years; $79(41.6 \%)$ were female. The mean follow-up was $75.0 \pm 18.0$ months. GTR was achieved in $127(66.8 \%)$ patients. In multivariate analysis, age $(p=$ $0.04)$, preoperative tumor volume ( $p=0.03)$, Knosp score $(p<0.001)$, and Ki-67 $(p=0.03)$ were significant predictors of STR. In patients with GTR, the probability of recurrence at 5 and 10 years was $3.9 \%$ and $4.7 \%$, and the probability of requiring treatment for recurrence was $0.79 \%$ and $1.6 \%$, respectively. In 63 patients who underwent STR, 6 (9.5\%) received early postoperative radiation and did not experience progression, while the remaining $57(90.5 \%)$ were observed. Of these, the probability of disease progression at 5 and 10 years was $21 \%$ and $24.5 \%$, respectively, and the probability of requiring additional treatment for progression was $17.5 \%$ and $21 \%$. Predictors of recurrence or progression in the entire group were Knosp score $(p<0.001)$ and elevated Ki-67 ( $p=0.03)$. Significant predictors of progression after STR in those who did not receive early radiotherapy were cavernous sinus location $(p<0.05)$ and tumor size $>1.0 \mathrm{~cm}^{3}(p=$ 0.005).

CONCLUSIONS Following GTR for nonfunctioning pituitary adenomas, the 10 -year chance of recurrence is low and the need for treatment even lower. After STR, although upfront radiation therapy may prevent progression, even without radiotherapy, the need for intervention at 10 years is only approximately $20 \%$ and a period of observation may be warranted to prevent unnecessary prophylactic radiation therapy. Tumor volume $>1 \mathrm{~cm}^{3}$, Knosp score $\geq 3$, and Ki-67 $\geq 3 \%$ may be useful metrics to prompt closer follow-up or justify early prophylactic radiation therapy.

https://thejns.org/doi/abs/10.3171/2019.11.JNS192457

KEYWORDS endoscopic; long-term outcomes; non-hormone producing; follow-up; pituitary adenoma; transsphenoidal; macroadenoma; endonasal; pituitary surgery

$\mathrm{N}$ ONFUNCTIONING pituitary adenomas are benign, generally slow-growing tumors known to have a great heterogeneity in clinical behavior, histopathological features, growth rates, and invasion into surrounding structures. ${ }^{3}$ These factors render the prediction of their natural history quite challenging. Treatment is indicated to relieve symptoms of mass effect or to prevent such symptoms if significant growth is observed. Given the relatively low morbidity of transsphenoidal surgery, operative intervention is often the first line of therapy. Once surgery is

ABBREVIATIONS ACTH = adrenocorticotrophic hormone; EES = endoscopic endonasal surgery; FSH = follicle-stimulating hormone; GH = growth hormone; GTR = grosstotal resection; IGF-1 = insulin-like growth factor-1; LH = luteinizing hormone; PRL = prolactin; STR = subtotal resection; TSH = thyroid-stimulating hormone.

SUBMITTED September 18, 2019. ACCEPTED November 20, 2019.

INCLUDE WHEN CITING Published online January 31, 2020; DOI: 10.3171/2019.11.JNS192457. 
completed, either tumors are observed or, if significant residual tumor remains, patients may undergo radiation therapy to prevent further growth. A thorough understanding of the recurrence rates of completely resected tumors and the progression rates of subtotally resected tumors is required to counsel patients on the frequency of postoperative imaging and the likelihood of requiring additional intervention in their remaining lifetime. These decisions should be derived from long-term data in large populations of patients with adequate follow-up.

Over the past 20 years, endoscopic endonasal surgery (EES) has grown in popularity for removing pituitary tumors, and short-term outcome studies have demonstrated higher rates of resection, particularly for larger macroadenomas with invasion into the adjacent parasellar compartments. ${ }^{38}$ In theory, more radical debulking of large tumors and higher rates of gross-total resection (GTR) may impact long-term recurrence rates and the need for prophylactic radiation therapy or the frequency of postoperative imaging. In this paper, we present a large series of patients with nonfunctioning macroadenomas removed through EES and provide long-term outcome data for more than 5 years of follow-up. It is the general policy at Weill Cornell not to offer upfront radiation therapy unless there is regrowth of tumor, and thus some data on the natural history of subtotally resected tumors are also presented. It is our hope that these findings will help guide clinicians with patient counseling and management.

\section{Methods \\ Patient Population}

All patients with nonfunctioning pituitary macroadenomas who underwent EES by our senior author (T.H.S.) between June 2003 and December 2014 were reviewed. IRB approval was obtained for this study. In order to provide a more accurate picture of the long-term outcome, only patients with $\geq 5$ years of postoperative follow-up were included. Nonfunctioning pituitary adenomas were defined by 1) the presence of a sellar mass $>1 \mathrm{~cm}$ in any dimension; and 2) the absence of elevated serum prolactin $(\mathrm{PRL})>200 \mathrm{ng} / \mathrm{mL}$, growth hormone $(\mathrm{GH})$, insulin-like growth factor-1 (IGF-1), cortisol, and adrenocorticotrophic hormone (ACTH), along with no clinical suspicion for Cushing disease.

\section{Data Collection}

A total of 190 patients met the inclusion criteria. Electronic medical records were reviewed and included preoperative and postoperative clinic visits, inpatient records, laboratory results, the operative report, and radiological images and reports. Preoperative data abstracted from medical records included demographic data, medical history, clinical examination, and endocrine status. All patients underwent a baseline preoperative pituitary panel that included serum cortisol, free thyroxine, thyroid-stimulating hormone (TSH), ACTH, GH, IGF-1, PRL, luteinizing hormone ( $\mathrm{LH})$, follicle-stimulating hormone (FSH), testosterone (in males), and estradiol (in females); if there was suspicion for Cushing disease, further biochemical evaluation was conducted. Preoperative radiological as- sessment included tumor volume (estimated according to the equation $(\mathrm{A} \times \mathrm{B} \times \mathrm{C}) / 2$ and extension and invasion into the suprasellar cistern (Hardy classification), cavernous sinus (Knosp classification), or sphenoid sinus. ${ }^{18}$

Perioperative outcomes (histology, complications, and extent of resection) and long-term outcomes (endocrine status, visual outcomes, and recurrence/progression rates) were also recorded. Diabetes insipidus was considered permanent if there was a need to continue desmopressin at the last follow-up. Extent of resection was determined as GTR or subtotal resection (STR) based on immediate postoperative MRI. Recurrence was defined as at least a $0.1-\mathrm{cm}^{3}$ growth of adenoma after GTR. Progression was defined by more than a $25 \%$ increase in the volume of residual tumor after STR compared with its size on early postoperative images. Regression was considered as at least a 25\% decrease in the volume during follow-up after STR.

\section{Statistical Analysis}

All data were analyzed using SPSS (version 26.0, IBM Corp.). A $p$ value $<0.05$ was considered statistically significant. Descriptive statistics were collected for all variables. Parametric data are given as mean \pm SD and compared using an independent-samples t-test. Nominal (categorical) data were compared using the chi-square test. Multivariate logistic regression models were designed to attempt to identify predictors of extent of resection and recurrence/regression/progression. Variables with a minimum of 10 cases and $\alpha<0.05$ in univariate analysis were included in multivariate models. For purposes of multivariate analysis, preoperative tumor size and $\mathrm{Ki}$ 67 were converted into nominal variables by percentiles, with tumor size converted to small ( $0-33$ rd percentile, $<$ $3 \mathrm{~cm}$ ), medium (34th-66th percentile, 3-8 cm), or large (67th-99th percentile, $>8 \mathrm{~cm}$ ) and Ki-67 into low (0-2.9) or high ( $\geq 3)$, and Knosp score into low (1 or 2 ) or high (3 or 4$)$.

Kaplan-Meier curves were created to calculate the probability of recurrence or progression, and the log-rank test was performed to compare the risk of tumor recurrence or progression based on the several variables listed above.

\section{Results}

\section{Patient Demographics, Clinical Presentation, and Tumor Characteristics}

Cases were drawn from a prospective database accrued between 2003 and 2014. During this time period, there were 235 EES procedures for resection of nonfunctioning pituitary adenomas. Of these patients, 190 had $\geq 5$ years of follow-up with a mean of $73.7 \pm 18.3$ months and form the basis of this study. The mean age was $63.8 \pm 13.2$ years, and $41.6 \%(n=79)$ of patients were female (Table 1). The most common presenting symptoms were visual complaints $(62.4 \%)$, headaches $(41.6 \%)$, and cranial nerve deficits $(2.1 \%)$. There were $19(10.0 \%)$ reoperations. The average tumor volume was $8.6 \pm 11.8 \mathrm{~cm}^{3}$. Sphenoid sinus extension was present in 5.8\% and suprasellar extension in 96.8\%. Chiasmal compression was present in $86.8 \%$ and cavernous sinus invasion in $34.2 \%$ of patients. Suprasellar extension $(\mathrm{p}=0.001)$ and chiasmal compression $(\mathrm{p}=$ 
TABLE 1. Demographics, clinical presentation, tumor characteristics, and postoperative outcomes

\begin{tabular}{|c|c|}
\hline & Value \\
\hline Mean age, yrs & $63.8 \pm 13.2$ \\
\hline Female sex & $79(41.6)$ \\
\hline \multicolumn{2}{|l|}{ Clinical presentation } \\
\hline Incidental & $56(29.5)$ \\
\hline Symptomatic & $134(70.5)$ \\
\hline Visual & 119 \\
\hline Headache & 79 \\
\hline Panhypopituitarism & 19 \\
\hline CN deficit & 4 \\
\hline Mean preop tumor size, $\mathrm{cm}^{3}$ & $8.6 \pm 11.8$ \\
\hline Suprasellar extension & $184(96.8)$ \\
\hline Chiasmal compression & $165(86.8)$ \\
\hline Cavernous sinus invasion & $65(34.2)$ \\
\hline Sphenoid sinus invasion & $11(5.8)$ \\
\hline \multicolumn{2}{|c|}{ Hardy classification scale for suprasellar extension } \\
\hline 0 & $7(3.7)$ \\
\hline A & $71(37.4)$ \\
\hline B & $61(32.1)$ \\
\hline C & $45(23.7)$ \\
\hline $\mathrm{D}$ & $6(3.2)$ \\
\hline \multicolumn{2}{|l|}{ Knosp score } \\
\hline 1 & $13(6.8)$ \\
\hline 2 & $20(10.5)$ \\
\hline 3 & $20(10.5)$ \\
\hline 4 & $12(6.3)$ \\
\hline \multicolumn{2}{|l|}{ Postop outcome } \\
\hline \multicolumn{2}{|l|}{ Vision } \\
\hline Stable & $88(46.3)$ \\
\hline Improved & $97(51.1)$ \\
\hline Worse & $5(2.6)$ \\
\hline $\mathrm{DI}$ & $16(8.4)$ \\
\hline Temporary & $6(3.2)$ \\
\hline Permanent & $10(5.3)$ \\
\hline Hematoma & $2(1.1)$ \\
\hline CSF leak & $6(3.2)$ \\
\hline
\end{tabular}

$\mathrm{CN}=$ cranial nerve; $\mathrm{DI}$ = diabetes insipidus.

Values are presented as the number of patients (\%) unless otherwise indicated. Mean values are presented as the mean \pm SD.

0.02 ) were significantly more likely in primary than in the revision surgeries (Table 2). The Hardy classification and Knosp score are shown in Table 1.

\section{Perioperative Outcomes}

All patients underwent EES for their pituitary adenoma. Extended transsphenoidal approaches were used in $83(43.7 \%)$ patients (transcavernous $21.1 \%$, transplanum $35.8 \%$, transclival $2.1 \%$ ). Immunohistochemistry was positive for $\mathrm{LH}$ in $25.1 \%$, FSH in $27.7 \%$, ACTH in $8.4 \%$, PRL in $7.3 \%$, TSH in $3.1 \%$, and $\mathrm{GH}$ in $2.6 \%$. The mean $\mathrm{Ki}-67$
TABLE 2. Comparison of demographics, postoperative outcome, and long-term follow-up between primary and revision cases

\begin{tabular}{|c|c|c|c|}
\hline & $\begin{array}{c}\text { Primary } \\
\text { Cases } \\
(n=171)\end{array}$ & $\begin{array}{c}\text { Revision } \\
\text { Cases } \\
(n=19)\end{array}$ & $p$ Value \\
\hline Mean age, yrs & $63.6 \pm 13.2$ & $65.4 \pm 13.3$ & 0.55 \\
\hline \multicolumn{4}{|l|}{ Sex } \\
\hline Male & $105(61.4)$ & $6(31.6)$ & \multirow{2}{*}{0.06} \\
\hline Female & $66(38.6)$ & $13(68.4)$ & \\
\hline \multicolumn{4}{|l|}{ Preop clinical data } \\
\hline Visual complaints & $109(63.7)$ & $10(52.6)$ & 0.34 \\
\hline CN deficit & $4(2.3)$ & 0 & NA \\
\hline \multicolumn{4}{|l|}{ Preop tumor characteristics } \\
\hline Mean vol, $\mathrm{cm}^{3}$ & $8.7 \pm 10.6$ & $8.5 \pm 19.8$ & \\
\hline Suprasellar extension & $169(98.8)$ & $15(78.9)$ & 0.001 \\
\hline Chiasmal compression & $151(88.3)$ & $14(73.7)$ & 0.02 \\
\hline Cavernous sinus invasion & $58(33.9)$ & $7(36.8)$ & 0.79 \\
\hline Sphenoid sinus invasion & $9(5.3)$ & $2(10.5)$ & 0.35 \\
\hline \multicolumn{4}{|l|}{ Postop outcome } \\
\hline \multicolumn{4}{|l|}{ Vision } \\
\hline Stable & $74(43.2)$ & $14(73.6)$ & \multirow{3}{*}{0.03} \\
\hline Improved & $92(53.8)$ & $5(26.3)$ & \\
\hline Worse & $5(2.9)$ & 0 & \\
\hline DI & $12(7.0)$ & $4(21.1)$ & 0.03 \\
\hline \multicolumn{4}{|l|}{ Postop endocrine } \\
\hline Hypopituitarism & $28(16.4)$ & $8(42.1)$ & \multirow{4}{*}{0.01} \\
\hline Hypogonadism & $16(9.4)$ & $1(5.3)$ & \\
\hline Hypothyroidism & $2(1.2)$ & $2(10.5)$ & \\
\hline Hypocortisolism & $3(1.8)$ & 0 & \\
\hline Hematoma & $2(1.2)$ & 0 & NA \\
\hline CSF leak & $6(3.5)$ & 0 & NA \\
\hline \multicolumn{4}{|l|}{ Extent of resection } \\
\hline GTR & $116(67.8)$ & $11(57.9)$ & \multirow{2}{*}{0.38} \\
\hline STR & $55(32.2)$ & $8(42.1)$ & \\
\hline
\end{tabular}

NA = not applicable.

Values are presented as the number of patients (\%) unless otherwise indicated. Mean values are presented as the mean \pm SD.

was $2.57 \pm 2.32$. Postoperative CSF leakage occurred in 6 (3.2\%) patients and was successfully treated with a lumbar drain postoperatively in 5 patients; $1(0.5 \%)$ patient required endoscopic exploration and repair. Surprisingly, all CSF leaks occurred following first-time operations and none after reoperations (Table 2). Postoperative hematoma requiring surgical evacuation occurred in $2(1.1 \%)$ patients.

Visual symptoms improved in $97(51.1 \%)$ patients while deterioration occurred in $5(2.6 \%)$. The rate of visual improvement was significantly higher in first-time surgeries than in revisions (53.8\% vs $26.3 \%, \mathrm{p}=0.03$ ) (Table 2 ). A total of $10(5.3 \%)$ patients developed new hypopituitarism after surgery, while the other $26(13.7 \%)$ patients with postoperative hypopituitarism had endocrine dysfunction preoperatively (Table 3 ). Postoperative diabetes insipidus was observed in 16 cases $(8.4 \%)$, more commonly after 
TABLE 3. Perioperative endocrine status

\begin{tabular}{lccccc}
\hline & \multicolumn{5}{c}{ No. of Patients (\%) } \\
\cline { 2 - 6 } & $\begin{array}{c}\text { At Last } \\
\text { Preop }\end{array}$ & Follow-Up & Improved & Stable & Worse \\
\hline Hypopituitarism & $19(10.0)$ & $36(19.0)$ & 2 & 17 & 0 \\
\hline Hypogonadism & $23(12.1)$ & $17(9.0)$ & 4 & 13 & 6 \\
\hline Hypothyroidism & $5(2.6)$ & $3(1.6)$ & 0 & 3 & 2 \\
\hline Hypocortisolism & $3(1.6)$ & $3(1.6)$ & 1 & 2 & 0 \\
\hline Mixed & $5(2.6)$ & $6(3.1)$ & 1 & 3 & 1 \\
\hline Normal function & $135(71.1)$ & $117(61.6) \dagger$ & 0 & 117 & $18^{*}$ \\
\hline
\end{tabular}

* Postoperative dysfunction in 18 patients: 10 with panhypopituitarism, 6 with hypogonadism, 1 with hypocortisolism, and 1 with hypogonadism and hypothyroidism.

† Eight patients (4.2\%) with preoperative endocrine dysfunction improved postoperatively.

reoperations $(21.1 \%$ vs $7 \%, \mathrm{p}=0.03)$ (Table 2$)$, resulting in permanent diabetes insipidus in only $10(5.3 \%)$ patients (Table 1). Anterior pituitary dysfunction was seen more commonly in reoperations than in first-time surgeries $(\mathrm{p}$ $=0.01)($ Table 2$)$.

\section{Extent of Resection}

GTR was achieved in $127(66.8 \%)$ patients and STR in $63(33.2 \%)$ patients (Table 4). There was no significant difference in GTR rates between primary operations and reoperations (Table 2). In a univariate analysis, preoperative tumor size $(p=0.002)$, Knosp score $(p<0.001)$, cavernous sinus invasion $(\mathrm{p}<0.001)$, sphenoid sinus invasion $(\mathrm{p}=0.03)$, and Ki-67 $(\mathrm{p}=0.03)$ were significant predictors of extent of resection (Table 5). The variables "cavernous sinus invasion" and "sphenoid sinus invasion"

TABLE 4. Extent of tumor resection and long-term follow-up status

\begin{tabular}{lcc}
\hline & GTR & STR \\
\hline No. of patients & $127(66.8)$ & $63(33.2)$ \\
\hline Mean follow-up, mos & $75.0 \pm 18.0$ & $73.8 \pm 16.6$ \\
\hline Upfront RT & 0 & $6(9.5)$ \\
\hline$\quad$ Stable & $121(95.3)$ & $43(68.3)$ \\
\hline Recurrence & $6(4.7)$ & NA \\
\hline$\quad$ Progression & NA & $14(22.2)$ \\
\hline$\quad$ Regression & NA & $6(9.5)$ \\
\hline $\begin{array}{l}\text { Mean time to recurrence or progression, } \\
\text { mos }\end{array}$ & $40.7 \pm 33.3$ & $47.8 \pm 23.3$ \\
\hline $\begin{array}{l}\text { Recurrence or progression requiring } \\
\text { intervention }\end{array}$ & $2(1.6)$ & $12(19.0)$ \\
\hline Recurrence or progression management & & \\
\hline$\quad$ RT & $1(0.8)$ & $9(14.3)$ \\
\hline$\quad$ Surgery + RT & $1(0.8)$ & $3(4.8)$ \\
\hline RT radothapy. & &
\end{tabular}

$\mathrm{RT}=$ radiotherapy.

Values are presented as the number of patients (\%) unless otherwise indicated. Mean values are presented as the mean \pm SD.
TABLE 5. Univariate factors associated with extent of resection

\begin{tabular}{|c|c|c|c|}
\hline & GTR & STR & $\mathrm{p}$ Value \\
\hline Preop visual deficits & 59.0 & 69.8 & 0.15 \\
\hline Mean preop tumor size, $\mathrm{cm}^{3}$ & $6.5 \pm 8.3$ & $12.9 \pm 15.9$ & 0.004 \\
\hline Preop tumor size & & & 0.002 \\
\hline Small $\left(<3 \mathrm{~cm}^{3}\right)$ & 77.8 & 22.2 & \\
\hline Medium $\left(3-8 \mathrm{~cm}^{3}\right)$ & 70.6 & 29.4 & \\
\hline Large $\left(>8 \mathrm{~cm}^{3}\right)$ & 48.1 & 51.9 & \\
\hline Knosp score & & & $<0.001$ \\
\hline Low (1 or 2) & 96.1 & 54.0 & \\
\hline High (3 or 4) & 3.9 & 46.0 & \\
\hline Suprasellar extension & 97.6 & 95.2 & 0.4 \\
\hline Cavernous sinus invasion & 19.7 & 63.5 & $<0.001$ \\
\hline Sphenoid sinus invasion & 3.1 & 11.1 & 0.03 \\
\hline $\mathrm{GH}$ & 2.4 & 3.2 & 0.7 \\
\hline PRL & 7.2 & 7.9 & 0.8 \\
\hline ACTH & 8.8 & 7.9 & 0.8 \\
\hline TSH & 2.4 & 4.9 & 0.4 \\
\hline Mean Ki-67 & 2.3 & 3.1 & 0.04 \\
\hline Ki-67 & & & 0.03 \\
\hline $1-2.9 \%$ & 40.5 & 31.8 & \\
\hline$\geq 3 \%$ & 18.9 & 36.5 & \\
\hline
\end{tabular}

Values are presented as percentages unless otherwise indicated. Mean values are presented as the mean \pm SD.

did not meet criteria (low sample size) for entry into the multivariate model. In multivariate analysis, statistically significant $(\mathrm{p}<0.05)$ predictors of STR were age (OR 1.03 per year), large (top tercile, $>8 \mathrm{~cm}^{3}$ ) preoperative tumor size (OR 2.9), and Knosp score 3 or 4 (OR 15.1, reference score 1-2) (Table 6). Ki-67 was no longer a predictor

TABLE 6. Multivariate predictors of extent of resection

\begin{tabular}{|c|c|c|}
\hline & OR & $p$ Value \\
\hline \multicolumn{3}{|l|}{ All } \\
\hline Age & 1.03 & 0.04 \\
\hline \multicolumn{3}{|l|}{ Preop tumor size } \\
\hline Small $\left(<3 \mathrm{~cm}^{3}\right)$ & Reference & \\
\hline Medium $\left(3-8 \mathrm{~cm}^{3}\right)$ & 1.3 & 0.5 \\
\hline Large $\left(>8 \mathrm{~cm}^{3}\right)$ & 2.9 & 0.03 \\
\hline Knosp score & 15.1 & $<0.001$ \\
\hline Ki-67 & 1.09 & 0.4 \\
\hline \multicolumn{3}{|l|}{ w/ Knosp score omitted } \\
\hline Age & 1.03 & 0.07 \\
\hline \multicolumn{3}{|l|}{ Preop tumor size } \\
\hline Small $\left(<3 \mathrm{~cm}^{3}\right)$ & Reference & \\
\hline Medium $\left(3-8 \mathrm{~cm}^{3}\right)$ & 1.4 & 0.4 \\
\hline Large $\left(>8 \mathrm{~cm}^{3}\right)$ & 4.7 & $<0.001$ \\
\hline Ki-67 & 1.2 & 0.03 \\
\hline Knosp score & Omitted & Omitted \\
\hline
\end{tabular}



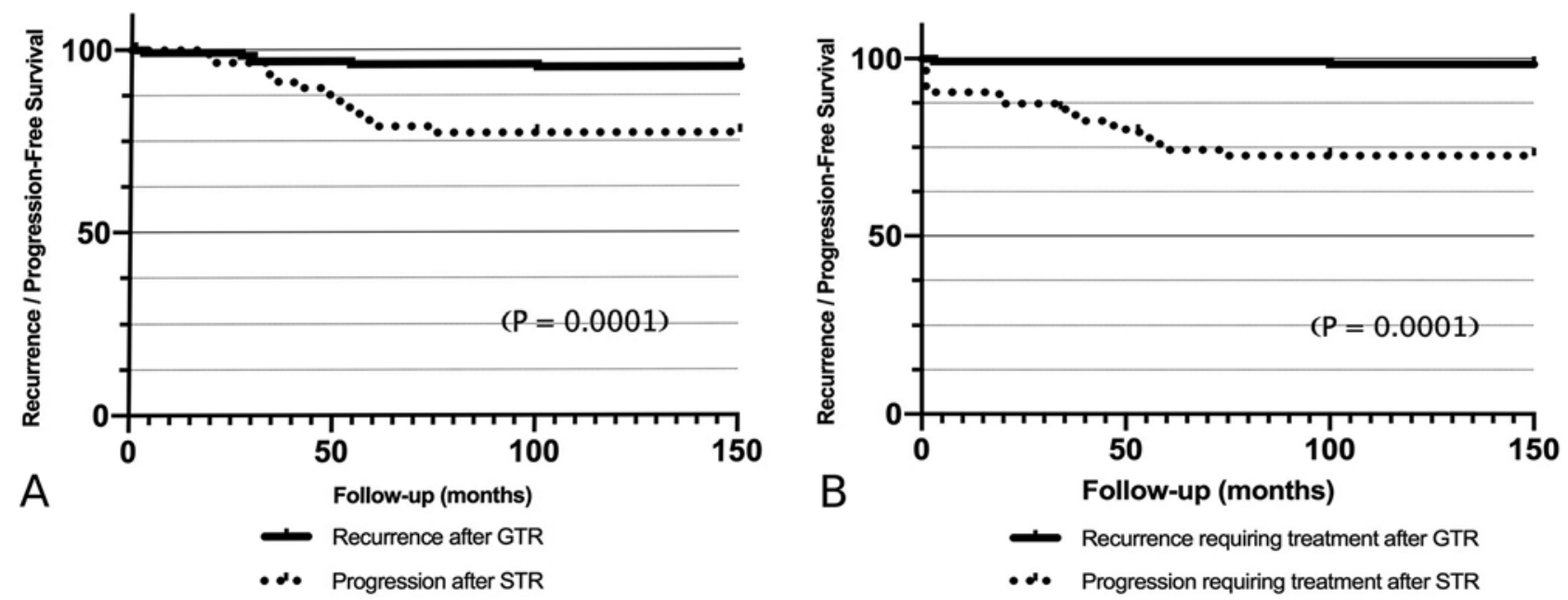

FIG. 1. Rates of recurrence following GTR or progression following STR (A) and rates of need for treatment following GTR versus $\operatorname{STR}(\mathrm{B})$

of STR when included in the multivariate analysis due to colinear interaction with the Knosp score. In a separate model excluding the Knosp score, Ki-67 was a significant predictor of STR (OR 1.2 per additional 1 point, $\mathrm{p}=0.03$ ) (Table 6).

\section{Recurrence or Progression of Disease}

Of the 127 patients with GTR, radiographic recurrence was seen in $6(4.7 \%)$ with an average follow-up duration of $75.0 \pm 18.0$ months. The mean time to recurrence was $41 \pm 33.3$ months. Among these patients, 4 were observed
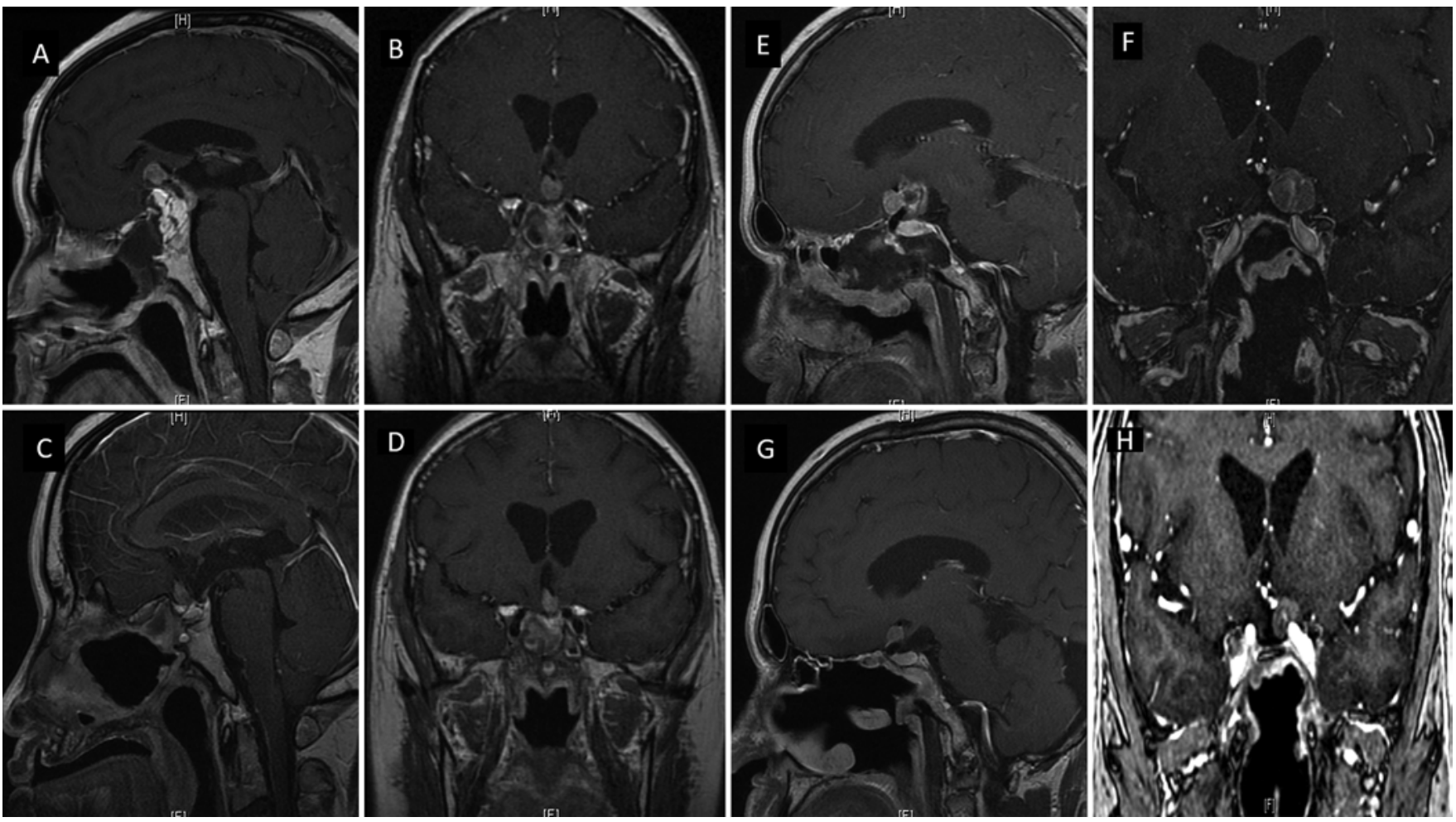

FIG. 2. Serial MR images showing diminution in size of residual tumor after STR. A-D: Patient 1. Immediate postoperative sagittal (A) and coronal (B) MR images showing residual pituitary macroadenoma with some suprasellar extension. Follow-up sagittal (C) and coronal (D) MR images obtained 75 months after resection, showing cavity shrinkage and regression of the residual tumor. E-H: Patient 2. Sagittal (E) and coronal (F) MR images obtained at the 3-month follow-up, showing suprasellar residual surrounding the internal carotid artery. Follow-up sagittal $(G)$ and coronal $(H)$ MR images obtained 36 months after endoscopic transsphenoidal resection, showing regression of the residual tumor. 
TABLE 7. Univariate and multivariate analyses of factors associated with recurrence or progression for the entire cohort

\begin{tabular}{|c|c|c|c|c|}
\hline & \multicolumn{2}{|l|}{ Univariate Analysis } & \multicolumn{2}{|c|}{ Multivariate Analysis } \\
\hline & Recurrence/Progression, \% & p Value & OR & p Value \\
\hline All patients $(n=190)$ & 13.7 & & & \\
\hline Preop visual deficit & & 0.2 & & 0.68 \\
\hline No & 9.9 & & Reference & \\
\hline Yes & 16.0 & & 1.2 & \\
\hline Preop tumor size & & 0.09 & & 0.38 \\
\hline Lower $2 / 3$ tercile & 10.9 & & Reference & \\
\hline Upper $1 / 3$ tercile $\left(>8 \mathrm{~cm}^{3}\right)$ & 20.4 & & 1.6 & \\
\hline Knosp score & & $<0.001$ & & 0.01 \\
\hline $1-2$ & 9.0 & & Reference & \\
\hline $3-4$ & 35.3 & & 3.7 & \\
\hline Ki-67 & & 0.03 & & 0.13 \\
\hline $0-2.9 \%$ (lower 50th percentile) & 7.5 & & Reference & \\
\hline$\geq 3 \%$ (upper 50th percentile) & 18.2 & & 2.2 & \\
\hline Revision surgery & & 0.09 & & 0.06 \\
\hline No & 12.3 & & Reference & \\
\hline Yes & 26.3 & & 3.3 & \\
\hline \multicolumn{5}{|l|}{$\mathrm{IHC}$ staining } \\
\hline TSH positive & 20.1 & 0.09 & 3.1 & 0.08 \\
\hline ACTH positive & 9.5 & 0.8 & & \\
\hline PRL positive & 10.8 & 0.6 & & \\
\hline GH positive & 15 & 0.5 & & \\
\hline
\end{tabular}

$\mathrm{IHC}=$ immunohistochemistry.

without further treatment, 1 underwent repeat EES and radiosurgery, and 1 received radiosurgery only (Table 4). Thus, only $1.6 \%(2 / 127)$ required treatment. Following GTR, the 5- and 10-year probability of recurrence was $3.9 \%$ and $4.7 \%$ (Fig. 1), and the probability of requiring additional treatment for recurrence was $0.79 \%$ and $1.6 \%$ (Fig. 1), respectively.

In the 63 patients with STR, $43(68.3 \%)$ were observed without any further growth, $6(9.5 \%)$ received upfront prophylactic radiosurgery, $6(9.5 \%)$ patients had radiographic tumor regression (Fig. 2), and 14 (22.2\%) had radiographic progression. The average follow-up duration was $73.8 \pm$ 16.6 months, and the mean time to progression was $48 \pm$ 23.3 months. The average size of the residual tumors that received radiation therapy was $1.8 \mathrm{~cm}^{3}$ compared with $0.8 \mathrm{~cm}^{3}$ for those that were observed. The 6 patients who received upfront prophylactic radiation therapy to the residual tumor did not experience progression. Of the 14 patients with progression, 2 had minimal progression that did not require treatment, whereas 12 patients required treatment; 3 underwent revision surgery and radiation therapy, whereas 9 had radiotherapy only (Table 4). Hence, of the 63 patients with STR only, $18(28.6 \%)$ required additional treatment other than observation (which includes the 6 who had early prophylactic radiation). Following STR (including the 6 patients who received early prophylactic postoperative radiation), the 5- and 10-year probability of disease progression was $19.1 \%$ and $22.2 \%$, respectively, and the probability of receiving treatment after STR (including early prophylactic radiotherapy) was $25.4 \%$ and $28.6 \%$, respectively (Fig. 1).

For the entire cohort, univariate predictors for recurrence or progression were high (3 or 4) Knosp score ( $p$ $<0.001)$ and high $(\geq 3 \%) \mathrm{Ki}-67(\mathrm{p}=0.03)$ (Table 5). Tumor size $>8 \mathrm{~cm}^{3}$ and revision surgery also trended toward significance $(\mathrm{p}=0.09)$ (Table 7$)$. Kaplan-Meier curves showing the impact of these variables on recurrence and/ or progression are shown in Fig. 3. In multivariate analysis, Knosp score $(\mathrm{p}=0.01)$ was the only significant predictor for recurrence or progression, but revision surgery trended toward significance $(\mathrm{p}=0.06)$ (Table 7$)$.

We found that only TSH-stained adenomas trended toward an increase in recurrence or progression in univariate analysis $(\mathrm{p}=0.09)$ and in multivariate analysis $(\mathrm{p}=0.08)$ (Table 7), whereas other immunohistochemical staining, including ACTH-stained adenomas, did not show such a predilection.

\section{Disease Progression in Patients Following STR Excluding Those Who Received Early Radiotherapy}

Following STR, excluding patients who had early prophylactic radiation therapy, the 5- and 10-year probability of disease progression was $21 \%$ and $24.5 \%$ and the probability of requiring additional treatment for progression was $17.5 \%$ and $21 \%$, respectively. In subgroup analysis of 

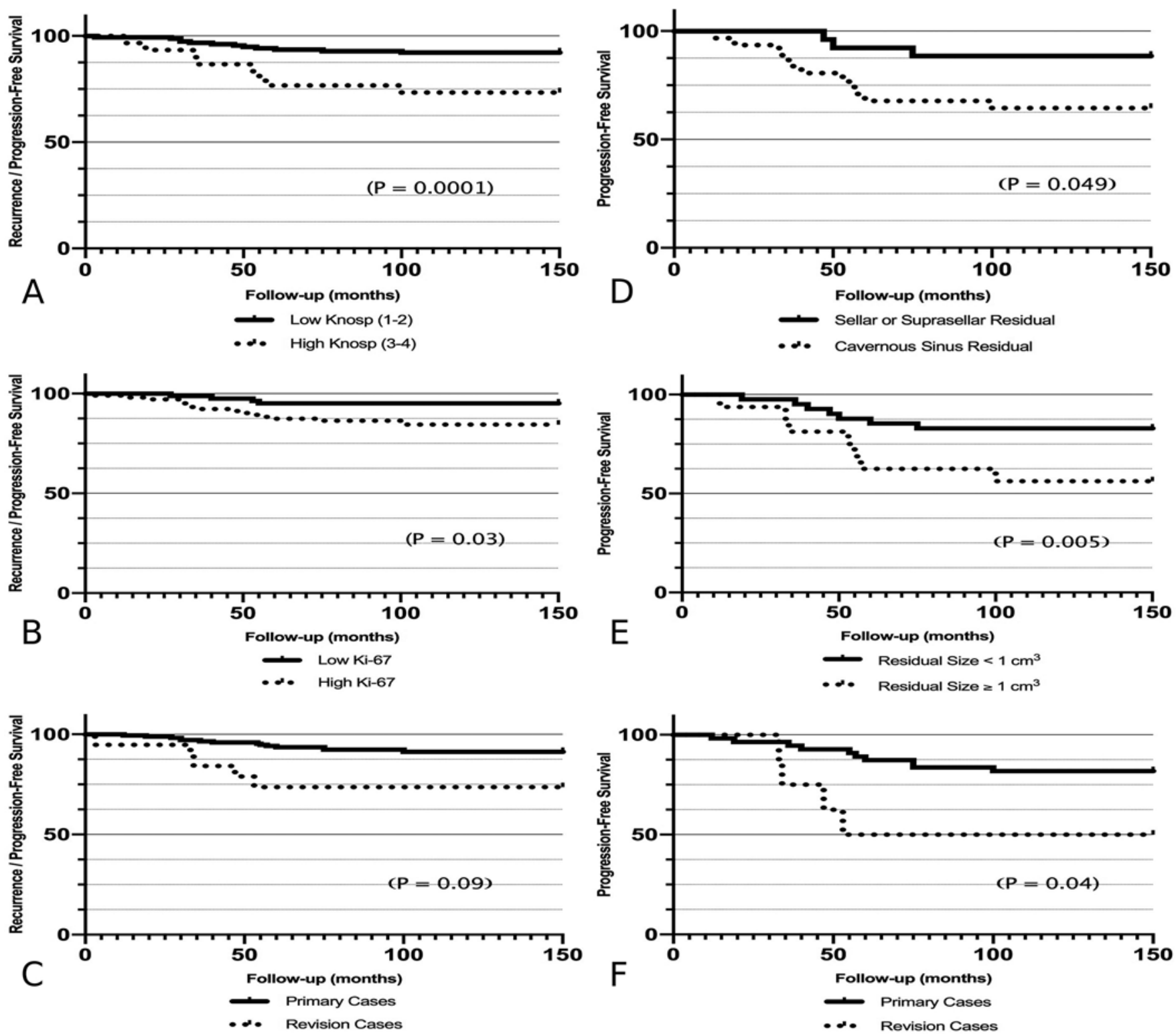

FIG. 3. Predictors of recurrence/progression-free survival in the entire cohort (A-C) and predictors of progression-free survival after STR after excluding the patients with upfront prophylactic radiotherapy (D-F).

these STR patients who did not receive early prophylactic radiation therapy, factors associated with progression were postoperative residual size $>1 \mathrm{~cm}^{3}(50 \%$ vs $14.3 \%$, p $=0.005$ ), residual mass located laterally (cavernous sinus or middle cranial fossa) versus midline (sellar, suprasellar) (31.4\% vs $10.7 \%, p=0.049)$, and revision surgery versus primary surgery $(50 \%$ vs $18.2 \%, p=0.04)($ Table 8$)$. In multivariate analysis, these factors trended toward significance (Table 8). Kaplan-Meier curves showing the impact of these variables on progression are shown in Fig. 3.

\section{Discussion}

This study demonstrates that the 10 -year recurrence rate following EES GTR for nonfunctioning pituitary adenomas is quite low $(<5 \%)$. Moreover, the need for treatment at 10 years is even lower, roughly $1.6 \%$. These data are not only lower than most of the long-term data previously published in the literature (Table 9) but also useful in counseling patients and reassuring them once GTR has been established on postoperative imaging. Moreover, if STR is achieved, most tumors can be observed and will not grow; in fact, some may regress. The need for intervention in this scenario is roughly $30 \%$, and most of these interventions occur within 5 years in patients with larger tumors $\left(>1 \mathrm{~cm}^{3}\right)$ invading the cavernous sinus with $\mathrm{Ki}-67 \geq 3 \%$. These data can be used to potentially avoid unnecessary prophylactic radiation therapy for patients with residual tumors and also guide clinicians to direct certain patients to early prophylactic radiation therapy who are at high risk of progression. 
TABLE 8. Univariate and multivariate factors associated with progression following STR, excluding patients who received early prophylactic radiation therapy

\begin{tabular}{|c|c|c|c|c|}
\hline & \multicolumn{2}{|c|}{ Univariate Analysis } & \multicolumn{2}{|c|}{ Multivariate Analysis } \\
\hline & Progression & $p$ Value & OR & $p$ Value \\
\hline \multicolumn{5}{|l|}{ Total patients $(n=63)$} \\
\hline No. w/ progression (\%) & $14(22.2)$ & & & \\
\hline Postop residual & & & & 0.07 \\
\hline$<1.0 \mathrm{~cm}^{3}$ & 14.3 & 0.005 & Reference & \\
\hline$>1.0 \mathrm{~cm}^{3}$ & 50.0 & & 2.9 & \\
\hline Residual site & & 0.049 & & 0.10 \\
\hline Midline (sellar/suprasellar) & 10.7 & & Reference & \\
\hline Lateral (cavernous sinus) & 31.4 & & 3.7 & \\
\hline Ki-67 & & 0.28 & & \\
\hline $0-2.9 \%$ (lower 50th percentile) & 14.3 & & & \\
\hline$\geq 3 \%$ (upper 50th percentile) & 26.2 & & & \\
\hline Revision surgery & & 0.04 & & 0.08 \\
\hline No & 18.2 & & Reference & \\
\hline Yes & 50.0 & & 5.3 & \\
\hline
\end{tabular}

Recurrence following complete GTR of non-hormoneproducing pituitary adenomas is likely due to microscopic cellular invasion into surrounding dura that is not visualized radiologically or intraoperatively. Meij et al. ${ }^{27}$ found such microscopic invasion in up to $46 \%$ of dural specimens, particularly in larger tumors. In studies with limited follow-up, recurrence rates of $0 \%$ have been reported, but these studies lack adequate long-term data. ${ }^{10,11,21,32}$ The rate of recurrence after microscopic transsphenoidal surgery with long-term follow-up has been reported to range anywhere from $6 \%$ to $20 \% .{ }^{10}$ For instance, Dekkers et al. and Chang et al. reported rates of $19 \%$ and $9 \%$, respectively, according to the 10-year Kaplan-Meier estimate. ${ }^{2,4}$ Longterm outcomes following EES for pituitary adenomas have shown recurrence rates up to $10.7 \%-25.0 \%$ (Table 9).,22,37 Dallapiazza et al. and Levy et al. reported rates of $20 \%$ and $25 \%$, respectively, according to the 10-year Kaplan-Meier estimate. Our study, which established extent of resection with postoperative MRI, revealed a much lower 10-year recurrence rate of $4.7 \%$. These results support the efficacy of achieving complete GTR using extended endoscopic approaches and support our earlier findings on extent of resection in both first-time operations and reoperations using shorter-term outcome data., ${ }^{7,13,19,29,30}$

Reports of progression rates after STR are much more variable due to heterogeneity of inclusion criteria, tumor characteristics, definitions of progression, and duration of follow-up..$^{15}$ In a series of 80 patients, Dallapiazza et al. ${ }^{3}$ reported a progression rate of $52 \%$ with a mean follow-up of 72 months. On the other hand, Seltzer et al. ${ }^{37}$ reported a progression rate of $8.3 \%$ in a group of 24 patients with a mean follow-up of 61 months. Paluzzi et al. ${ }^{32}$ reported a progression rate of $63.9 \%$ with a mean follow-up of 3.1 years. The majority of long-term studies of microscopic transsphenoidal surgery reported progression rates less than 50\% (Table 9). These rates do not include those for patients who received early radiation therapy following
STR. The reported 10-year progression rates following EES for pituitary adenomas were 79\% (Dallapiazza et al. ${ }^{3}$ ) and 60\% (Levy et al. ${ }^{22}$ ), respectively. In our cohort, we report a lower 10-year progression rate of $22 \%$ for the entire cohort, including a small subgroup that received prophylactic radiation therapy, or $24.5 \%$ for patients who did not receive early radiotherapy. The lower rates of recurrence even after STR in this series might be attributed to several factors. Many of our STR patients had a very small amount of residual tumor $\left(<1 \mathrm{~cm}^{3}\right)$, and, as we have shown that smaller residuals are less likely to recur, our recurrence rates might be lower than previously published. In addition, the delivery of early postoperative radiation therapy is generally not randomized and thus there may be variable amounts of selection bias in different series regarding who received early radiation therapy and who was followed expectantly. Even in our series, the average tumor volume in STR patients who underwent radiation therapy early was slightly larger than that in those who were observed. Resolution of this ambiguity would require that all patients who receive STR be deprived of early radiation and followed closely, which may not be in the best interest of the patients since there is clearly a subgroup with a higher risk of recurrence, namely those with larger residual tumors, higher Ki-67, and cavernous sinus invasion.

Identification of clinical, radiological, and histopathological factors associated with the degree of resection and recurrence/progression is important for patient counseling and surgical decision-making. In our series, STR was more likely for tumors of larger size, significant cavernous sinus invasion (per Knosp score), and elevated Ki-67. Furthermore, we found that tumor invasiveness (high Knosp score and Ki-67) and larger residual tumor $\left(>1 \mathrm{~cm}^{3}\right)$ were also associated with a higher risk of progression. These findings are supported by prior literature. Dallapiazza et al. ${ }^{3}$ also identified cavernous sinus invasion (Knosp scoring) as a predictor of tumor recurrence. Other authors have 


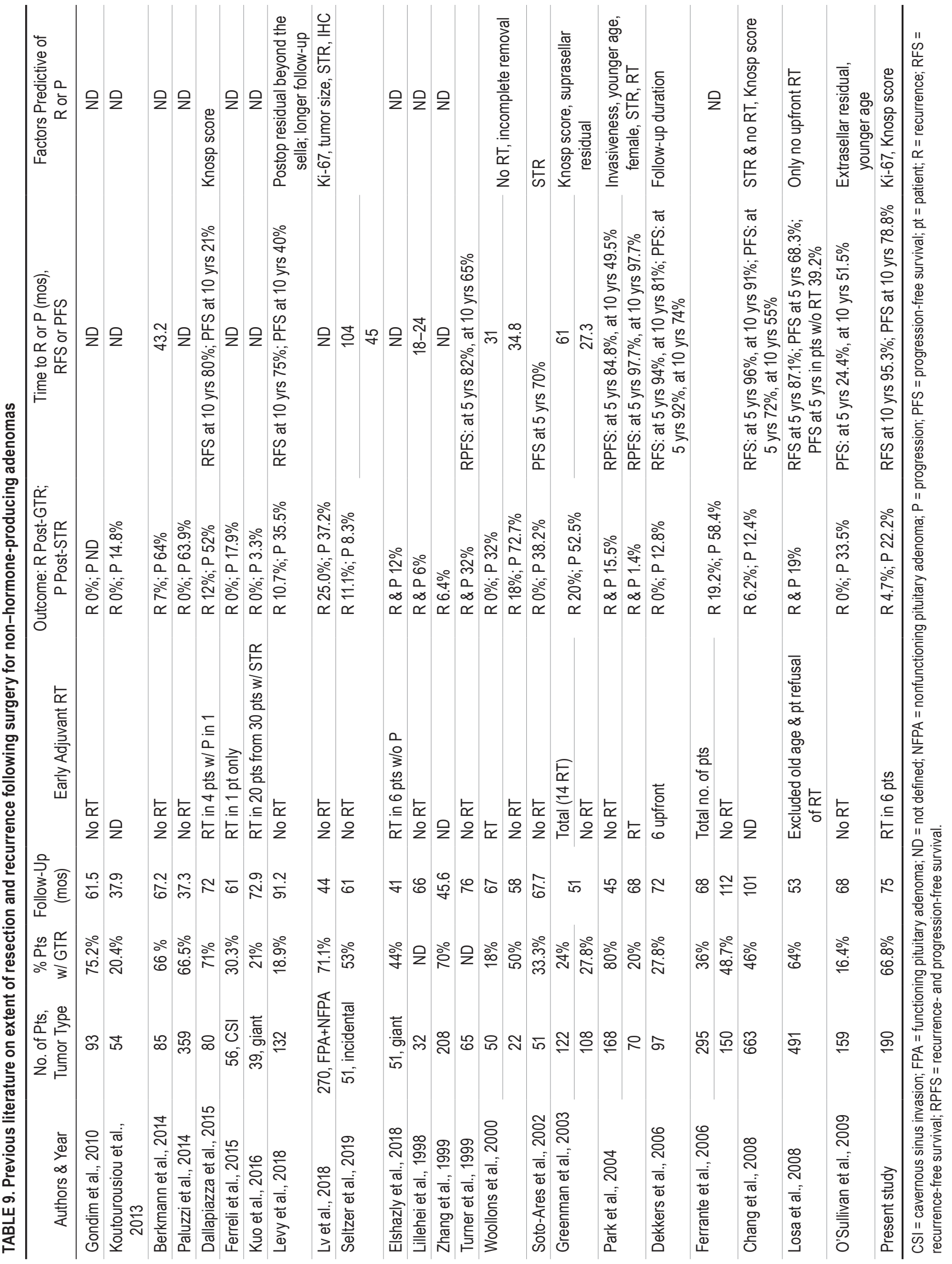


also demonstrated progression rates of up to $17 \%$ for residual tumor in the cavernous sinus. ${ }^{9} \mathrm{Lv}$ et al. identified tumor volume and the size of the residual as predictors of progression. ${ }^{26}$ Similarly, macroadenomas, compared with microadenomas, have demonstrated increased incidence of regrowth. ${ }^{15,17,28,42}$

The optimal timing of radiation therapy for residual tumors remains unclear because of the uncertainty of the growth rate of these tumors. Although some authors have advocated early radiotherapy for residual endocrine-inactive adenomas, the risk of delayed pituitary failure after radiation is high, with the majority of patients developing new endocrinopathy after 5-10 years. ${ }^{34}$ Sadik et al. reported a hypopituitarism rate of $22 \%$ in an early radiotherapy cohort monitored for a mean of 40 months. ${ }^{36}$ In a longterm study by Höybye et al., the rate was $72 \%$ with a mean follow-up of 17 years. ${ }^{14}$

Park et al ${ }^{33}$ studied the use of early radiation treatment versus expectant management for residual nonfunctioning adenomas. They found only a 10 -year $2.3 \%$ recurrence rate with early treatment compared with a $50 \%$ rate of tumor progression if tumors were followed up clinically without radiation treatment. Upfront radiotherapy is recommended for incurable functioning adenomas and after reoperation for recurrent adenomas. ${ }^{11}$ Our study indicates that while early radiation therapy likely reduces the risk of progression, the majority of patients can be observed without intervention. Such a policy would significantly reduce the rate of treatment-related iatrogenic hypopituitarism. In our series, the rate of progression was higher in tumors invading the cavernous sinus, with a tumor volume $>1 \mathrm{~cm}^{3}$, and with increased Ki-67. Therefore, the decision should be tailored individually according to patient age, residual tumor in proximity to the optic apparatus, hormonal status, and predictors of recurrence. ${ }^{6}$

In 2004, the WHO created a class of adenomas called "atypical" that are characterized by increased mitotic index, elevated Ki-67, and high p53 immunoactivity. ${ }^{5}$ These tumors were believed to have a higher growth rate and a more aggressive natural history and tended to occur in younger patients and in hormone-producing tumors and have a higher recurrence rate ${ }^{35}$ after treatment. In 2013, a French collaborative study of prognostic factors of pituitary tumors introduced invasiveness as a criterion predicting more aggressive growth and recurrence..$^{40}$ This classification has been criticized since it appeared to be based on the assumption that invasive tumors are hardly resected. ${ }^{16}$ Yet, as we have shown, using expanded endonasal techniques, many of these invasive tumors can be completely resected with minimal or no residual.,13,19,29,30 Nevertheless, in 2017 the term "atypical adenoma" was abandoned by the WHO due to a lack of adequate data to support this unique classification. ${ }^{24}$ While many prior studies of aggressiveness have lumped hormone-producing and non-hormone-producing tumors together, this current series examines uniquely non-hormone-producing tumors and utilizes an aggressive expanded endonasal approach to maximize extent of resection. We confirm that invasiveness, size, and elevated Ki-67 are all predictors of STR and/or recurrence after surgery. Since the diagnosis of a more aggressive subtype of non-hormone-producing adenoma is a postoperative diagnosis, these criteria cannot be used to guide initial therapy but rather postoperative management. For this reason, we have limited our recommendations to use these criteria to make recommendations regarding which patients might benefit from early prophylactic radiation therapy and which patients can be observed with little risk of eventual intervention.

\section{Limitations}

The present analysis is drawn from a retrospective cohort analysis and, thus, cannot be utilized to establish causality between risk factors and outcomes. Inherent to a retrospective study design, our data collection was limited by the accuracy and completeness of the electronic medical record. Our study was the largest series to date detailing long-term outcomes following EES for pituitary adenomas. However, analyses aimed at identifying predictors of recurrence and progression were limited by sample size of the subcohorts. We encourage the design of a multicenter prospective study to further study long-term outcomes and predictive analytics in patients undergoing EES for pituitary adenomas. ${ }^{32}$

\section{Conclusions}

After GTR for nonfunctioning pituitary adenomas, the 10 -year chance of recurrence is low and the need for treatment even lower. After STR, although upfront radiation therapy may prevent progression, even without it the need for intervention at 10 years is only approximately $20 \%$, and a period of observation may be warranted to prevent unnecessary prophylactic radiation therapy. Tumor volume $>1 \mathrm{~cm}^{3}$, Knosp score $\geq 3$, and Ki-67 $\geq 3 \%$ may be useful metrics to prompt closer follow-up or justify early prophylactic radiation therapy.

\section{References}

1. Berkmann S, Schlaffer S, Nimsky C, Fahlbusch R, Buchfelder M: Follow-up and long-term outcome of nonfunctioning pituitary adenoma operated by transsphenoidal surgery with intraoperative high-field magnetic resonance imaging. Acta Neurochir (Wien) 156:2233-2243, 2014

2. Chang EF, Zada G, Kim S, Lamborn KR, Quinones-Hinojosa A, Tyrrell JB, et al: Long-term recurrence and mortality after surgery and adjuvant radiotherapy for nonfunctional pituitary adenomas. J Neurosurg 108:736-745, 2008

3. Dallapiazza RF, Grober Y, Starke RM, Laws ER Jr, Jane JA Jr: Long-term results of endonasal endoscopic transsphenoidal resection of nonfunctioning pituitary macroadenomas. Neurosurgery 76:42-53, 2015

4. Dekkers OM, Pereira AM, Roelfsema F, Voormolen JH, Neelis KJ, Schroijen MA, et al: Observation alone after transsphenoidal surgery for nonfunctioning pituitary macroadenoma. J Clin Endocrinol Metab 91:1796-1801, 2006

5. DeLellis RA, Lloyd RV, Heitz PU, Eng C (eds): Pathology and Genetics of Tumours of Endocrine Organs: World Health Organization Classification of Tumours, ed 3. Oxford: Oxford University Press, 2004, Vol 8

6. Elshazly K, Kshettry VR, Farrell CJ, Nyquist G, Rosen M, Evans JJ: Clinical outcomes after endoscopic endonasal resection of giant pituitary adenomas. World Neurosurg 114:e447-e456, 2018

7. Esquenazi Y, Essayed WI, Singh H, Mauer E, Ahmed M, Christos PJ, et al: Endoscopic endonasal versus microscopic 
transsphenoidal surgery for recurrent and/or residual pituitary adenomas. World Neurosurg 101:186-195, 2017

8. Ferrante E, Ferraroni M, Castrignanò T, Menicatti L, Anagni M, Reimondo G, et al: Non-functioning pituitary adenoma database: a useful resource to improve the clinical management of pituitary tumors. Eur J Endocrinol 155:823-829, 2006

9. Ferreli F, Turri-Zanoni M, Canevari FR, Battaglia P, Bignami M, Castelnuovo P, et al: Endoscopic endonasal management of non-functioning pituitary adenomas with cavernous sinus invasion: a 10-year experience. Rhinology 53:308-316, 2015

10. Gondim JA, Almeida JP, Albuquerque LA, Schops M, Gomes E, Ferraz T, et al: Endoscopic endonasal approach for pituitary adenoma: surgical complications in 301 patients. Pituitary 14:174-183, 2011

11. Gondim JA, Schops M, de Almeida JP, de Albuquerque LA, Gomes E, Ferraz T, et al: Endoscopic endonasal transsphenoidal surgery: surgical results of 228 pituitary adenomas treated in a pituitary center. Pituitary 13:68-77, 2010

12. Greenman Y, Ouaknine G, Veshchev I, Reider-Groswasser II, Segev Y, Stern N: Postoperative surveillance of clinically nonfunctioning pituitary macroadenomas: markers of tumour quiescence and regrowth. Clin Endocrinol (Oxf) 58:763769,2003

13. Hofstetter CP, Nanaszko MJ, Mubita LL, Tsiouris J, Anand VK, Schwartz TH: Volumetric classification of pituitary macroadenomas predicts outcome and morbidity following endoscopic endonasal transsphenoidal surgery. Pituitary 15:450-463, 2012

14. Höybye C, Grenbäck E, Rähn T, Degerblad M, Thorén M, Hulting AL: Adrenocorticotropic hormone-producing pituitary tumors: 12- to 22-year follow-up after treatment with stereotactic radiosurgery. Neurosurgery 49:284-292, 2001

15. Iglesias P, Arcano K, Triviño V, García-Sancho P, Díez JJ, Cordido F, et al: Non-functioning pituitary adenoma underwent surgery: a multicenter retrospective study over the last four decades (1977-2015). Eur J Intern Med 41:62-67, 2017

16. Inoshita N, Nishioka H: The 2017 WHO classification of pituitary adenoma: overview and comments. Brain Tumor Pathol 35:51-56, 2018

17. Ioachimescu AG, Eiland L, Chhabra VS, Mastrogianakis GM, Schniederjan MJ, Brat D, et al: Silent corticotroph adenomas: Emory University cohort and comparison with ACTH-negative nonfunctioning pituitary adenomas. Neurosurgery 71:296-304, 2012

18. Knosp E, Steiner E, Kitz K, Matula C: Pituitary adenomas with invasion of the cavernous sinus space: a magnetic resonance imaging classification compared with surgical findings. Neurosurgery 33:610-618, 1993

19. Komotar RJ, Starke RM, Raper DM, Anand VK, Schwartz TH: Endoscopic endonasal compared with microscopic transsphenoidal and open transcranial resection of giant pituitary adenomas. Pituitary 15:150-159, 2012

20. Koutourousiou M, Gardner PA, Fernandez-Miranda JC, Paluzzi A, Wang EW, Snyderman CH: Endoscopic endonasal surgery for giant pituitary adenomas: advantages and limitations. J Neurosurg 118:621-631, 2013

21. Kuo CH, Yen YS, Wu JC, Chang PY, Chang HK, Tu TH, et al: Primary endoscopic transnasal transsphenoidal surgery for giant pituitary adenoma. World Neurosurg 91:121-128, 2016

22. Levy MJ, Robertson IJ, Khalk N, Vitello S, Reddy N, Bhake $\mathrm{R}$, et al: Long-term follow-up of a large prospective cohort of patients with nonfunctioning pituitary adenomas: the outcome of a conservative management policy. Clin Endocrinol (Oxf) 89:354-359, 2018

23. Lillehei KO, Kirschman DL, Kleinschmidt-DeMasters BK, Ridgway EC: Reassessment of the role of radiation therapy in the treatment of endocrine-inactive pituitary macroadenomas. Neurosurgery 43:432-439, 1998
24. Lopes MBS: The 2017 World Health Organization classification of tumors of the pituitary gland: a summary. Acta Neuropathol 134:521-535, 2017

25. Losa M, Mortini P, Barzaghi R, Ribotto P, Terreni MR, Marzoli SB, et al: Early results of surgery in patients with nonfunctioning pituitary adenoma and analysis of the risk of tumor recurrence. J Neurosurg 108:525-532, 2008

26. Lv L, Yin S, Zhou P, Hu Y, Chen C, Ma W, et al: Clinical and pathologic characteristics predicted the postoperative recurrence and progression of pituitary adenoma: a retrospective study with 10 years follow-up. World Neurosurg 118:e428e435, 2018

27. Meij BP, Lopes MB, Ellegala DB, Alden TD, Laws ER Jr: The long-term significance of microscopic dural invasion in 354 patients with pituitary adenomas treated with transsphenoidal surgery. J Neurosurg 96:195-208, 2002

28. Molitch ME: Pituitary tumours: pituitary incidentalomas. Best Pract Res Clin Endocrinol Metab 23:667-675, 2009

29. Muskens IS, Zamanipoor Najafabadi AH, Briceno V, Lamba N, Senders JT, van Furth WR, et al: Visual outcomes after endoscopic endonasal pituitary adenoma resection: a systematic review and meta-analysis. Pituitary 20:539-552, 2017

30. Negm HM, Al-Mahfoudh R, Pai M, Singh H, Cohen S, Dhandapani S, et al: Reoperative endoscopic endonasal surgery for residual or recurrent pituitary adenomas. J Neurosurg 127:397-408, 2017

31. O'Sullivan EP, Woods C, Glynn N, Behan LA, Crowley R, O'Kelly P, et al: The natural history of surgically treated but radiotherapy-naïve nonfunctioning pituitary adenomas. Clin Endocrinol (Oxf) 71:709-714, 2009

32. Paluzzi A, Fernandez-Miranda JC, Tonya Stefko S, Challinor $\mathrm{S}$, Snyderman $\mathrm{CH}$, Gardner PA: Endoscopic endonasal approach for pituitary adenomas: a series of 555 patients. Pituitary 17:307-319, 2014

33. Park P, Chandler WF, Barkan AL, Orrego JJ, Cowan JA, Griffith KA, et al: The role of radiation therapy after surgical resection of nonfunctional pituitary macroadenomas. Neurosurgery 55:100-107, 2004

34. Pomeraniec IJ, Dallapiazza RF, Xu Z, Jane JA Jr, Sheehan JP: Early versus late Gamma Knife radiosurgery following transsphenoidal resection for nonfunctioning pituitary macroadenomas: a matched cohort study. J Neurosurg 125:202-212, 2016

35. Rutkowski MJ, Alward RM, Chen R, Wagner J, Jahangiri A, Southwell DG, et al: Atypical pituitary adenoma: a clinicopathologic case series. J Neurosurg 128:1058-1065, 2018

36. Sadik ZHA, Voormolen EHJ, Depauw PRAM, Burhani B, Nieuwlaat WA, Verheul J, et al: Treatment of nonfunctional pituitary adenoma postoperative remnants: adjuvant or delayed Gamma Knife radiosurgery? World Neurosurg 100:361-368, 2017

37. Seltzer J, Wedemeyer MA, Bonney PA, Carmichael JD, Weiss M, Zada G: Outcomes following transsphenoidal surgical management of incidental pituitary adenomas: a series of 52 patients over a 17-year period. J Neurosurg 130:15841592, 2019

38. Smith ML, Patel SK, Choudhry OJ, Eloy JA, Liu JK: Evolution of a microsurgical to endoscopic practice for treatment of pituitary tumors and skull base lesions: importance of multidisciplinary team approach and learning curve. J Neurol Surg B 73:A191, 2012

39. Soto-Ares G, Cortet-Rudelli C, Assaker R, Boulinguez A, Dubest C, Dewailly D, et al: MRI protocol technique in the optimal therapeutic strategy of non-functioning pituitary adenomas. Eur J Endocrinol 146:179-186, 2002

40. Trouillas J, Roy P, Sturm N, Dantony E, Cortet-Rudelli C, Viennet G, et al: A new prognostic clinicopathological classification of pituitary adenomas: a multicentric case-control 
study of 410 patients with 8 years post-operative follow-up. Acta Neuropathol 126:123-135, 2013

41. Turner HE, Stratton IM, Byrne JV, Adams CBT, Wass JAH: Audit of selected patients with nonfunctioning pituitary adenomas treated without irradiation - a follow-up study. Clin Endocrinol (Oxf) 51:281-284, 1999

42. van Varsseveld NC, Bisschop PH, Biermasz NR, Pereira AM, Fliers E, Drent ML: A long-term follow-up study of eighteen patients with thyrotrophin-secreting pituitary adenomas. Clin Endocrinol (Oxf) 80:395-402, 2014

43. Woollons AC, Hunn MK, Rajapakse YR, Toomath R, Hamilton DA, Conaglen JV, et al: Non-functioning pituitary adenomas: indications for postoperative radiotherapy. Clin Endocrinol (Oxf) 53:713-717, 2000

44. Zhang X, Fei Z, Zhang J, Fu L, Zhang Z, Liu W, et al: Management of nonfunctioning pituitary adenomas with suprasellar extensions by transsphenoidal microsurgery. Surg Neurol 52:380-385, 1999

\section{Disclosures}

The authors report no conflict of interest concerning the materials or methods used in this study or the findings specified in this paper.

\section{Author Contributions}

Conception and design: Schwartz, Gerges, Rumalla, Younus, Elshamy, Dobri. Acquisition of data: Schwartz, Gerges, Godil, Younus, Kacker, Tabaee, Anand. Analysis and interpretation of data: Gerges, Godil, Younus, Dobri, Kacker, Tabaee, Anand. Drafting the article: Gerges, Rumalla, Younus, Dobri, Kacker, Tabaee, Anand. Critically revising the article: Gerges, Rumalla, Godil, Dobri, Kacker, Anand. Reviewed submitted version of manuscript: Schwartz, Gerges, Godil, Kacker, Anand. Approved the final version of the manuscript on behalf of all authors: Schwartz. Statistical analysis: Gerges, Rumalla, Godil, Dobri, Tabaee. Administrative/technical/material support: Gerges, Tabaee. Study supervision: Schwartz, Gerges, Rumalla, Godil, Younus, Elshamy.

\section{Correspondence}

Theodore H. Schwartz: Weill Cornell Medicine, NewYork-Presbyterian Hospital, New York, NY. schwarh@med.cornell.edu. 